\title{
AS CONFERÊNCIAS DE SAÚDE: ESPAÇOS DE INTERLOCUÇÃO PÚBLICA
}

\author{
Ricardo de Jesus Silveira \\ Professor do Departamento de Ciências Sociais da UEL \\ E-mail: silveirarj@uol.com.br
}

\begin{abstract}
Resumo
O texto é uma reflexão sobre as conferências de saúde de Londrina. Procura demonstrar que as conferências se caracterizam como espaço político, por excelência, pois vão além da mera construção de direitos sociais no âmbito da saúde. Correspondem a espaços que abrigam uma pluralidade de atores sociais e conflitos de interesses, permitindo a politização das questões sociais e, neste sentido, o pleno exercício da cidadania.
\end{abstract}

Palavras-chave: espaço público; democracia; cidadania.

s reflexões, aqui desenvolvidas, sobre as conferências de saúde têm como objetivo pensá-las do ponto de vista da cidadania. Não é, portanto, preocupação desenvolver uma abordagem que limite o foco da análise sobre a correlação de forças entre os atores que, obviamente, têm interesses não apenas conflitantes mas muitas vezes excludentes, como também, não poucas vezes, convergentes. Não que seja irrelevante considerar os atores participantes quanto à força e/ou ao potencial de que dispõem para arregimentar meios que os tornem capazes para impor a satisfação dos seus interesses, mas porque, consideradas do ponto de vista dos direitos, as questões mais pertinentes, assim nos parecem, são aquelas voltadas para as condições a partir das quais a cidadania pode ser exercida; trata-se de voltarmos mais para o como se governa e menos para quem governa.

O que está em questão na opção da abordagem feita é vislumbrar a possibilidade efetiva da constituição de uma sociabilidade democrática na sociedade brasileira (PAOLI, 1989). Trata-se, simultaneamente, não 
só de considerar as conferências como um espaço de interlocução pública, que abriga a pluralidade dos atores sociais e a diversidade de interesses a eles correspondentes, e por isso um espaço de conflitos e de acordos no qual se constroem as políticas públicas, como também de abordar as conferências do ponto de vista da cidadania o que corresponde a considerá-las como lugar da ação, do exercício da liberdade, da circulação de idéias e valores e do estabelecimento de novas identidades na construção de direitos sociais e, especialmente, de sujeitos sociais e políticos. De modo sintético, o exercício de direitos sociais não se dissocia de sua construção política.

O desenvolvimento dessa análise, que mais se caracteriza como o registro da leitura de um processo histórico em andamento, tomará como base empírica as cinco primeiras Conferências de Saúde de Londrina, cidade do norte paranaense, de 400 mil habitantes, cuja experiência tem sido destacada, tanto por um certo pioneirismo, marcado pelo envolvimento com o "movimento sanitário" que teve fundamental importância na construção da legislação constitucional de 1988 (MULLER NETO, 1991)' ${ }^{\prime}$, como pelo seu ativo movimento popular no âmbito do município - com a militância de jovens médicos sanitaristas, estudantes, trabalhadores da saúde - que articulado a outros movimentos e lideranças tem revelado uma forte presença e influência nas proposições das políticas de saúde através das conferências já realizadas.

Assim, a experiência das conferências de Londrina é perfeitamente adequada ao que aqui se propõe, justamente por ser representativa do movimento pela saúde pública que se vem desenvolvendo no Brasil a partir dos anos 70s. E mais do que isso, pelo fato das Conferências

\footnotetext{
I O movimento pela Reforma Sanitária, congregando jovens médicos, estudantes e trabalhadores do setor, bem como outros segmentos sociais, como sindicatos e entidades de classe que se somaram na crítica para a construção de uma saúde melhor, desenvolveu-se a partir dos anos 70 s, em sua fase mais recente, mas sem esquecer que o movimento tem origem em meados dos anos 50s. Todavia foi a partir da articulação entre secretários municipais de saúde de cidades de vários Estados que passaram a questionar a política vigente que o movimento ganhou impulso na fase de redemocratização dos anos $70 \mathrm{~s} / 80 \mathrm{~s}$, tornando-se o grande responsável por assegurar na Constituição de 1988 o estabelecimento da saúde como direito do cidadão e dever do Estado.
} 
terem sido, em quase todas as suas edições, um exemplo de participação ativa dos segmentos envolvidos, mostrando um processo rico de discussões a partir da defesa de interesses diversos, indicando um modo prático, possível de fazer política, sem que as posições divergentes resultem em impasses insanáveis.

Mas, a visão positiva, que aqui registramos, do processo participativo local não deve esconder que o mesmo é feito, também, de reações muitas vezes exacerbadas por parte dos atores participantes, em especial, dos representantes dos setores prestadores de serviços, cujos interesses são, na maioria das vezes, contrariados pelos interesses dos demais participantes. Um dado conhecido e relevante, neste caso, diz respeito ao fato de ser a remuneração dos serviços conveniados, quase sempre, em valor muito inferior ao praticado no mercado, criando-se obstáculos ao funcionamento satisfatório do sistema e constituindo-se argumento recorrente por parte do segmento dos prestadores como justificativa, muitas vezes, da má prestação de serviços.

Para a explicitação da reflexão proposta faremos, para o que aqui nos interessa, uma brevíssima consideração sobre a mudança organizacional havida no setor da saúde, particularmente, sobre a criação do SUS e o seu significado político, seguido do registro da experiência londrinense, de modo a ilustrar a politização das questões de saúde que, notoriamente, com a abertura dos espaços de interlocução - conferências e conselhos - tornaram-se, de modo não passageiro, questões públicas, o que quer dizer políticas, naquilo que tais questões têm de política, e por isso publicamente tratadas, e não questões meramente técnicas, tratadas de modo centralizado na repartição setorial afim, a partir de um "discurso competente" (CHAUÍ, 1993).

No registro dessa experiência, a atenção especial será dada à análise das proposições de políticas de usuários e prestadores de serviço que surgiram na $5^{\text {a }}$ Conferência, em outubro de 1997, com a finalidade de mostrar a riqueza de proposições fundadas em interesses diversos que o espaço público das conferências permite, evidenciando ser lugar de discussão e de legitimação de interesses, como de construção coletiva de políticas sociais, portanto, um espaço de cidadãos ativos. 
Por fim buscaremos ressaltar, na reflexão, a peculiaridade do espaço público que são as conferências, no sentido de mostrar que, para além de um lugar de construção de direitos sociais, como satisfação de necessidades, elas são lugar de liberdade, porque espaço organizado da política, e, portanto, de exercício da autonomia.

\section{Breve consideração sobre a mudança .}

A Constituição de 1988 foi, de fato, um marco na experiência da sociedade brasileira. Numa leitura possível, ela não representou somente o final de um processo de redemocratização, mas muito mais, foi o marco do início de uma nova sociedade, cuja diferença fundamental, em relação à que a precede, estava no fato da politização da vida social. Na prática isso significou, em alguns setores, a descentralização políticoadministrativa da ação pública institucional, com especial destaque para o setor da saúde².

Até há muito pouco tempo, a efetivação desse processo de mudança na vida pública da sociedade brasileira era impensável. Por essa razão deve-se observar que esta forma descentralizada de gerir os negócios públicos, com maior visibilidade no setor da saúde, pelo que se destaca a criação do Sistema Único de Saúde - SUS - foi a grande novidade consagrada na Constituição de 1988. Novidade porque o padrão da ação estatal foi sempre marcado pela centralização financeira e operacional, e se esse fato não chega a ser uma surpresa é porque nos anos que finalizam o período da redemocratização do país, os anos 80 s, as ações da Previdência Social, através do INAMPS, de triste memória, mostravam-se ineficazes pelo caráter perdulário da gestão dos seus gastos, pelo descontrole orçamentário, pela facilitação de um processo de fraudes que, sem dúvida, potencializado, entre outros fatores, pelos escassos recursos e pela incapacidade do Estado ao pautar-se por um modelo centralizado, produzindo como resultado uma

\footnotetext{
2 É ampla a discussão sobre a descentralização, no sentido de sua qualificação quanto à participação e à democracia. Apenas como registro vale citar: Teixeira (1990); Borja (1988); Neves (1987), Jacobi (1989).
} 
crescentc defiasagem entre oferta e demanda dos serviços de saúde, com as conseçiientes distorções evidenciadas na má remuneração dos serviços e na deterioração da infraestrutura existente, tornava previsível a mudança do sistema em face de sua evidente falência (DRAIBE; VIANA; SILVA, 1990 apud MULLER NETO, 1991).

Mas, o fracasso do modelo "estatal-privatista", desenhado na forma sempre mais precária do atendimento à saúde, não nos parece ser a causa suficiente da emergência de um processo de descentralização, no sentido da democratização da sociedade e do estado brasileiros, tal qual se desenvolveu a partir do final dos anos 70 s e durante os anos 80 s, resultando em mudanças na organização social e política que, de fato, indicavam-nos a possibilidade efetiva de construção de uma sociedade menos injusta.

Enfatiza-se, portanto, que as mudanças ocorridas não dizem respeito apenas à volta dos militares aos quartéis e ao restabelecimento do controle do Estado pelo poder civil através do sufrágio universal, elas foram muito mais significativas, pois essas mudanças, parecem, só poderiam ser resultado de uma experiência cuja duração viesse de um tempo mais longo do que o vivido durante o regime militar ${ }^{3}$.

O surgimento do SUS, por exemplo, só se torna plausível mediante a compreensão do movimento sanitário, cujo surgimento, nos anos 70 s, desencadeou um processo vitorioso de lutas de crescente significado político, cujas reivindicações foram posteriormente incorporadas à Constituição de 1988. A esse respeito destacam-se: a universalização da saúde com o que se confere direitos a todo cidadão, numa clara perspectiva da desmercadorização da saúde, face a face, usuário e prestador de serviços, ao atribuí-la como responsabilidade do Estado (OLIVEIRA, 1988; ESPING-ANDERSEN, 1991), a descentralização político-administrativa do planejamento dos serviços e do controle social com participação popular através das conferências e conselhos municipais, devolvendo a política à sociedade, lugar em que, a rigor, ela nunca deixou de ocupar, embora só em momentos

${ }^{3}$ Götz Ottmann (1995) mostra certa decepção dos estudiosos com relação aos movimentos populares dos anos 70/80, sugere que uma análise mais produtiva necessita pensar os movimentos a partir de "uma moldura temporal mais longa". 
esporádicos viesse à cena pública (LEFORT, 1987) e uma questão fundamental que só passa a ser percebida, com mais ênfase, a partir dos anos 90 , e que corresponde à compreensão da saúde como o "completo bem-estar físico, mental e social e não a simples ausência de doença", o que significou o re-direcionamento dos gastos, agora não mais para a atenção médico-hospitalar, mas para a atenção preventiva e promotora. (DIMITROV, 1996; MULLER NETO, 1991).

O que se quer enfatizar aqui é que esse processo de mudança resultou de uma longa resistência, porque, também, longa é a experiência de opressão sobre a maioria da população brasileira. Por essa razão, ao se buscar compreender esse processo a partir de uma leitura mais ampla no tempo, devemos ter em conta, por isso mesmo, que as reações não estão ausentes desse processo de mudanças, com um dado agravante, pois, talvez, mais do que em qualquer outra fase da história brasileira, o momento que se vive apresenta perspectivas efetivas de construção de uma nova sociedade.

\section{A experiência local}

Em Londrina, a primeira conferência de saúde ocorreu em 1989 , antecipando a própria criação efetiva do SUS e a regulamentação da institucionalização da participação popular no sistema de saúde, o que só seria assegurado, respectivamente, com as Leis Federais 8080/09/ 90 , e a $8142 / 12 / 90$.

A partir desta legislação, o repasse de recursos federais para o desenvolvimento das políticas locais passa a ser condicionado à integração ao sistema. Pode parecer um modo autoritário o condicionamento do repasse de recursos aos municípios mediante sua filiação ao SUS, na verdade, é o contrário o que ocorre, pois a definição da política nestes termos era uma aspiração dos movimentos da saúde, à medida em que assegura que as políticas locais e a conseqüente alocação de recursos não são feitas sem a participação popular.

Uma indicação positiva da experiência local, ainda que não suficiente, pode ser dada pela ativa participação dos diversos segmentos sociais nas conferências, tanto do ponto de vista 
quantitativo quanto qualitativo. No primeiro caso, basta verificarmos que nas conferências de 1995, 1997 e 1999 registrou-se uma média de 450 participantes. Destes, conforme a formação paritária da representação, 320 correspondem aos delegados divididos em: 50\% de usuários, $25 \%$ de trabalhadores da saúde, $12,5 \%$ de prestadores de serviços e $12,5 \%$ de representantes do gestor; o restante dos participantes dividem-se entre convidados e observadores, ambos com direito a voz, mas não a voto, uma vez que o voto é prerrogativa exclusiva dos delegados. Trata-se de uma representação que busca, obviamente, cobrir o conjunto dos segmentos sociais dos quais compõem-se a sociedade local; no caso dos usuários, os delegados são em regra lideranças de entidades civis, classistas ou não e militantes de movimentos populares; no caso dos trabalhadores da saúde, são lideranças do sindicato afim e de associações da categoria; no caso dos prestadores de serviço, são profissionais representantes de hospitais, de clínicas da rede privada conveniadas e do sindicato dos médicos, e no caso do gestor, são representantes do poder público, em geral, profissionais ligados à Autarquia de Saúde do Município.

A escolha dos delegados é feita nas pré-conferências de cada segmento, e destas saem as proposições de políticas a serem apresentadas e discutidas nas conferências propriamente ditas. Salientando que as proposições devem estar diretamente relacionadas ao tema da conferência e que este é definido pelo gestor em conformidade com o Conselho Municipal de Saúde.

A forma da escolha da representação por segmento é ilustrativa do modo democrático de como se estruturam as conferências. No caso dos usuários, por exemplo, dado que o número de delegados é fixo, cada entidade e/ou movimento indica representantes em número correspondente à participação que teve na pré-conferência. Essa forma é interessante porque, a priori, nenhuma entidade tem representação previamente assegurada, todas têm que mobilizar sua base e militância a fim de lograr o maior número possível de membros participantes como delegados, e o mesmo procedimento é acompanhado pelos demais segmentos.

Do ponto de vista qualitativo, as conferências que se seguiram, a cada dois anos, a partir de 1989 , refletem de modo claro a evolução do 
processo de discussões, conforme podemos verificar, a partir de umas poucas considerações sobre a temática desenvolvida pelas respectivas conferências. Assim temos, respectivamente, da primeira à sexta conferência estudada: "Políticas diretrizes e linhas de ação para implantação do Sistema Único de Saúde", com dois sub-temas: 1) A unificação dos serviços de saúde de Londrina e 2) Recursos humanos, materiais e financeiros para o Sistema Único de Saúde de Londrina. Temas que revelam a disposição na organização dos serviços de saúde pública nos termos preconizados pela política federal. Na conferência seguinte, com o tema: "Saúde Londrina", buscava-se fazer um balanço das condições de saúde no município para planejar e priorizar as ações. Na conferência seguinte, a terceira, com o tema: "Modelo Assistencial", as discussões buscaram, com a crítica à prática que se desenvolvia até aquele momento, a mudança na orientação das políticas. Esse momento coincidiu com a tomada do poder local pelo Partido dos Trabalhadores (PT), então articulado aos movimentos populares e, em particular, com o movimento pela reforma sanitária. A quarta conferência, realizada em 1995, com o tema: "A situação do Sistema Único de Saúde - SUS, alternativas e soluções”, e mais quatro sub-temas: 1) Situação do SUS em Londrina, 2) Financiamento do setor saúde, 3) Controle Social e, 4) Alternativas para a consolidação do SUS em Londrina, buscava, especialmente, consolidar o modelo de gestão da saúde no município. Dessas discussões destacam-se a preocupação em assegurar meios financeiros para sustentação do modelo de gestão e o efetivo envolvimento da população com a discussão sobre o necessário controle social da gestão dos serviços. Na conferência seguinte, com o tema: "Londrina, cidade saudável", e os sub-temas: 1) Município saudável, 2) Controle social do município saudável e, 3) Políticas de recursos humanos para o município saudável, registrava-se o ponto alto do processo de discussão das políticas de saúde para a cidade de Londrina. As discussões das proposições para a saúde, a partir do tema "cidade saudável", significou um salto qualitativo na maneira como as lideranças e os segmentos participantes passavam a pensar a questão da saúde; tratava-se de deslocar a atenção, antes voltada para o indivíduo, para a coletividade. Essa mudança (na verdade um salto dentro do processo de evolução das discussões sobre saúde) significou, 
evidentemente, mais do que mostrar-se sintonizada com o conceito de saúde como mais do que ausência de doenças, significou, de fato, a radicalização da politização da saúde ao expor o seu comprometimento interdependente com a estrutura socioeconômica. Ademais, a continuação das discussões sobre o controle social aliada à preocupação com a qualificação dos recursos humanos envolvidos com as questões da saúde indicava-nos que se estaria processando uma clara mudança do ponto de vista da cultura, uma maneira nova da sociedade local, por meio de suas representações, pensar-se a si mesma através da saúde ${ }^{4}$.

Observadas através dos temas que se sucederam, é certo considerar que as conferências trouxeram para a cena pública temas de fundamental importância para a reprodução social, problematizando questões de modo objetivo e claramente assegurando à população não apenas a possibilidade de opinar sobre as questões de saúde que já lhe chegavam prontas para serem aceitas ou rejeitadas, mas abrindo o espaço público a novas proposições e deliberações sobre a questão. Mas, não pode passar despercebida a ameaça à consolidação do SUS, como política há muito acalentada pelos setores progressistas da sociedade civil, dado o seu caráter de equiidade. Nesse sentido é evidente sua contraposição às políticas neoliberais, às quais há um notório alinhamento do governo federal, e, também, muito presentes no plano local as reações a qualquer avanço conquistado. Daí ser recorrente nas conferências a preocupação com o controle social e o financiamento público, em especial, para que a universalização, a equiidade e a integralidade não venham a ser desfiguradas por obstáculos interpostos, justamente, como reação à efetivação do sistema que, como já foi dito, está em flagrante desacordo com as regras neoliberais, pelas quais a saúde é tratada simplesmente como mercadoria.

Neste breve registro da experiência local, cabe ainda expor como se desenvolveu a dinâmica interna das conferências com relação ao

\footnotetext{
4 É interessante observar que o tema da $5^{\circ}$ Conferência, realizada em outubro de 97 , estava em plena sintonia com os demais movimentos da sociedade civil: com a questão dos "sem-terra", dos movimentos urbanos, de um modo geral e, de modo muito particular poder-se-ia dizer que a Eco 92 e/ou a Agenda 21 estaria refletida na Conferência de Saúde local.
} 
processo de discussão e deliberação. Assim, as cinco seções principais que as compõem, descritas em seguida, permite-nos ter uma idéia do espaço de discussões que caracterizam as conferências: Seção I Abertura, na qual se destaca a palestra principal sobre o tema da conferência, proferida por convidado especialista. (com espaço para debate entre palestrante e participantes). Seção II - Seminários ou palestras secundárias, na qual são proferidas também por especialistas convidados, as palestras que versam sobre os sub-temas (com espaço para debates entre palestrantes e participantes). Seção III - Discussão em grupo das proposições políticas oriundas das pré-conferências. As proposições dos diversos segmentos são previamente reunidas e classificadas por sub-temas pela comissão de sistematização e entregues aos grupos temáticos para discussão e deliberação preliminar. Os grupos são formados de acordo com o número de participantes, resultando em mais ou menos vinte grupo; o número de participantes por grupo também gira em torno de 20 pessoas. Cada grupo discute e delibera sobre as proposições de um determinado tema, assim, há mais de um grupo discutindo e deliberando sobre as proposições de um mesmo tema. Nas deliberações sobre cada proposição há quatro possibilidades: rejeição, aprovação, aprovação com supressão de parte, ou aprovação com adendo. Seção IV - Plenária deliberativa, na qual as proposições são votadas por todos os delegados. A votação é precedida do trabalho de sistematização, de modo que, nesta seção, sejam discutidas apenas as propostas que foram aprovadas com adendo ou supressão, cabendo, no caso, a manifestação favorável e contrária, com tempo razoável de fala, previamente definido, após o que se submetem à plenária para votação; as proposições rejeitadas não vão à plenária, a menos que algum delegado requeira por escrito, o que é submetido à deliberação da plenária para se saber se a proposição rejeitada nos grupos deve ser rediscutida e votada. Se aceita, a proposição volta à plenária e procedese, a partir daí, conforme os casos de proposições aprovadas com adendo ou supressão. Seção V - Plenária final, na qual o texto final é lido e aprovado, constando ainda desta seção as proposições de moções, que são rejeitadas ou aprovadas por aclamação.

Como é notório, é nas discussões em grupo e na plenária deliberativa que as divergências entre os segmentos se explicitam com 
mais nitidez. E, certamente, por isso se explica o fato dos segmentos distribuírem seus delegados em função dos interesses sobre as proposições, especialmente as mais polêmicas, levando-se em conta o preparo dos mesmos com relação à defesa dos seus pontos de vista.

No item seguinte, a exposição das proposições a ser feita permitirá uma melhor avaliação do conflito de idéias e de interesses, o que, para as reflexões propostas no início do artigo, tem a finalidade de expor a riqueza desse espaço público que são as conferências, ao abrigar uma pluralidade de atores e permitir, como espaço político organizado, o confronto dos mais diversos interesses.

\section{As conferências: espaço público e a explicitação de interesses}

Antes de apresentarmos as proposições de usuários e prestadores de serviço da $5^{\circ}$ Conferência para discussão, cabem algumas explicações: a escolha do segmento de usuários e prestadores de serviço se deve ao fato de serem segmentos com interesses, em regra, polarizados, permitindo, assim, uma visão mais ampla sobre as posições em relação aos problemas pertinentes à saúde; quanto à escolha da $5^{\circ}$ Conferência e não de outra, isso se deve ao fato de considerarmos esta conferência a mais rica do ponto de vista temático, o que certamente possibilita uma variedade de proposições por parte dos segmentos.

Assim, tendo como tema "Londrina cidade saudável", as proposições políticas oriundas das pré-conferências dos segmentos foram agrupadas em quatro temas e subtemas, conforme segue: Tema I - POLÍTICA DE PROMOÇÃO À SAÚDE E PREVENÇÃO DE ENFERMIDADES E ACIDENTES: 1) Ações educativas; 2) Ações sobre o meio ambiente; 3) Controle de substâncias geradoras de dependência; 4) Transporte, segurança e trânsito; 5) Saúde do trabalhador; 6) Saúde mental; 7) Saúde da criança e da mulher; 8) Medicamentos; 9) Organização de serviços; 10) Financiamento; e, 11) Políticas gerais; Tema II - POLÍTICA DE ATENÇÃO CURATIVA: 1) Atenção primária; 2) Atendimento secundário e terciário; 3 ) Saúde bucal; 4) Política de saúde mental; e, 5) Política de medicamentos; 
Tema III - CONTROLE SOCIAL; e, finalmente, Tema IV - POLÍTICA DERECURSOS HUMANOS.

De um total de 209 proposições políticas, 31 foram apresentadas pelos prestadores de serviço e 90 pelos usuários. A descrição completa das proposições de ambos os segmentos tornaria a exposição por demais extensa. Assim sendo, julgamos pertinente, sem prejuízo para a análise, destacar apenas dois dos temas: POLÍTICADEPROMOÇÃOÀ SAÚDEE PREVENÇÃODEENFERMIDADESEACIDENTESe;CONTROLESOCIAL.

Desse modo, resumidamente, das proposições dos prestadores de serviço para o tema "POLÍTICA DE PROMOÇÃO À SAÚDE E PREVENÇÃO DE ENFERMIDADES E ACIDENTES" temos, "Ações Educativas": - propostas para ações educativas e cursos de extensão sobre saúde básica a ser incluído nos currículos de $1^{\circ}, 2^{\circ}$ e $3^{\circ}$ graus; "Controle de Substâncias Geradoras de Dependência": - campanha comunitária contra drogas - bebidas alcoólicas, fumo, etc, e, - programa de fiscalização da venda de cigarros a menores; "Transporte Segurança e Trânsito": - implantação de serviço de prevenção e capacitação dos hospitais para acidente de trânsito, - melhoria do transporte com ambulância para remoção de emergência às UTIs; "Saúde Mental": - programa específico ao idoso, visando atendimento biopsíquico social; "Medicamentos": treinamento comunitário para adequado uso da fitoterapia, considerando os recursos que a população domina no dia-a-dia; "Organização dos Serviços": - criação de atendimento de urgência para pacientes com doenças crônico-degenerativas, - melhoria das Unidades Básicas de Saúde (UBS), com profissionais especializados e reavaliação das UBS para assegurar maior resolutibilidade para a rede primária de saúde; "Financiamento": - equiidade no repasse de recursos financeiros entre prestadores de serviços públicos e privados, adotando como critério a proporcionalidade de atendimentos do SUS, - incentivo financeiro aos prestadores de serviços para evitar paralisações nos serviços essenciais, - criação de uma central de custos do setor de saúde a ser controlada pelo Conselho Municipal de Saúde ; "Políticas Gerais": (conjuntamente a usuários e trabalhadores da saúde) política de saúde para população flutuante, com casas-abrigo para doentes sem residência fixa.

Para esse mesmo tema, os usuários apresentaram: “Ações Educativas": de caráter preventivo, - programas de educação e 
prevenção nas escolas de $1^{\circ}$ e $2^{\circ}$ graus sobre sexo, trânsito, prevenção contra drogas, doenças infecto-contagiosas (AIDS, DSTs), higiene, meio ambiente (utilização de produtos agrotóxicos), alimentar, sanitária e sobre legislação de saúde, com participação de toda a comunidade e não apenas do corpo discente das escolas; de caráter promotor: programa de hortas domésticas e comunitárias, - cultivo de plantas medicinais, - programa de puericultura para crianças sadias do meio rural e urbano, - programa de atendimento a crianças vítimas de violência, - adequação das creches às necessidades e demandas da população usuária e, - cartilha sobre serviços médicos das UBS; "Ações Sobre o Meio Ambiente": saneadora, - crematórios para animais, obrigatoriedade de incineradores para lixo hospitalar, - transferência da Cia de Asfalto para fora do perímetro urbano, - recuperação dos cursos d'água e drenagem das áreas alagadas; promotora, - projeto de reciclagem de lixo, - controle de vetores em ferros-velhos, borracharias, fundos de vale e terrenos baldios, - urbanização de fundos de vale e plantio de árvores frutíferas, - programa de limpeza pública e conscientização sobre a limpeza dos espaços urbanos, - cobertura de $100 \%$ da malha viária com pavimentação, rede de esgoto e água potável, - remoção e transferência de construções em áreas de risco e/ou inadequadas ao assentamento habitacional; disciplinadora, cumprimento da Lei Orgânica não permitindo loteamentos sem infraestrutura, - regularização de loteamentos, - controle da circulação de animais em vias públicas (respeitando-se a legislação de proteção aos animais), - rigor na vigilância sanitária; "Transportes, Segurança e Trânsito":- programa de segurança com relação ao trânsito nas imediações de escolas e creches, - melhoria da iluminação pública em toda a cidade, - policiamento nas escolas e UBS, - linha de ônibus bairro-hospitais, - transporte especial para doentes, - construção de terminal urbano na região oeste, - adequação dos transportes coletivos para os portadores de deficiências, - regionalização dos serviços de ambulância; "Saúde do Trabalhador": - implantação de um Centro de Referência de Saúde do Trabalhador, - programa de prevenção contra acidentes, - intensificação da vigilância municipal para controle das condições de saúde no trabalho; "Saúde Mental": - rigor no cumprimento da Lei 8842 (referente a cuidados permanentes com 
idosos); "Saúde da Criança e da Mulher": - implantação de programa de planejamento familiar (com garantia de acesso aos métodos anticoncepcionais, incluindo os de caráter definitivo: vasectomia e laqueadura), ampliação do programa Saúde da Família; "Medicamentos": - criação de programa de medicina alternativa (capacitando as famílias para o uso adequado dessa terapia); "Organização dos Serviços": - construção de hospital na região oeste, - estudo de construção do mini-hospital do distrito de Lerroville (voltado ao atendimento da população rural), programa médico para as reservas indígenas (com treinamento adequado aos profissionais com relação à cultura indígena); "Políticas Gerais": - projetos de emprego e renda, - programa da guarda-mirim com inclusão de meninas, - programa de habitação popular, - melhor adequação dos espaços físicos das escolas para as suas finalidades, programa de esportes e lazer nos bairros periféricos e na zona rural, ampliar o número de telefones públicos na periferia, - cursos profissionalizantes compatíveis com a política de desenvolvimento local, - implantação de ensino de $1^{\circ}$ e $2^{\circ}$ graus (supletivos) na zona rural, programa de alfabetização de todo londrinense, - criação de escolas especializadas para pessoas portadoras de deficiências, - rigor no controle do uso do solo para evitar danos ao meio ambiente.

Numa primeira aproximação parece evidente que a maioria das propostas de um e outro segmento está diretamente relacionada ao seu cotidiano, quer de trabalho, quer doméstico, o que certamente explica um número maior de propostas dos usuários, posto serem estes os diretos protagonistas das ações promotoras e preventivas. $\mathrm{O}$ fato dos usuários proporem crematório para animais é sintomático do fato da ausência dos serviços sanitários nos bairros da periferia, razão do porquê animais, como cachorro, por exemplo, permanecerem mortos e apodrecendo nas ruas, se, acaso, nenhum particular não tomar providência por conta própria. Da mesma forma, o fato dos prestadores estarem mais preocupados com suas condições de trabalho e remuneração correspondente, como questões que envolvem equipamentos e a organização dos mesmos, pode ser explicado pela vivência direta e mais próxima do problema.

Tais explicações, no entanto, advêm de impressões que simplificam a análise e deixam escapar questões importantes. É 
surprecndente, por exemplo, que os prestadores, embora disponham de conhecimentos muito mais desenvolvidos, não tenham formulado proposiçōes para subtemas importantes como "Ações sobre o Meio Ambiente" e "Saúde da Criança e da Mulher". Tratar-se-ia de insensibilidade, simplesmente? Certamente que sim, mas é mais que isso, é o não-comprometimento com o outro, é a ausência de um sentimento de dever público, que bem tem caracterizado a sociedade brasileira (CHAUÍ, 1993). Todavia, toda generalização tende a incorrer em erro, e por isso essa consideração não deve ficar ausente de uma análise $e^{5}$ mais circunstanciada.

Tais observações não têm a ilusão de que poderia ser diferente, de que deveria haver concordância entre os segmentos, pois quando ocorre fica claro tratar-se de questões em que não há conflito de interesses. Um exemplo são as proposições sobre "ações educativas", em que não há discordância entre os segmentos prestador de serviço e usuário, apenas que, enquanto os prestadores são sintéticos e econômicos em suas proposições educativas, os usuários são detalhistas e apresentam propostas mais diversificadas, abrangendo mais aspectos da mesma questão. Esse dado indica, para os usuários, a politização das questões que vivenciam e demonstra capacidade propositiva com muita riqueza, o que só poderia ser percebido em um espaço de interlocução com o público.

Está claro que o espaço das conferências é de conflito, mas enquanto espaço político organizado, e portanto institucionalizado, é também de legitimação do conflito ao assegurar que as proposições, de um ou outro segmento, se tornem políticas públicas depois de aceitas como justas pela maioria, pois é desse entendimento que o espaço público se faz público, uma vez que se torna um espaço comum, com o qual se identificam os participantes (ARENDT, 1990).

Também não há o que estranhar estarem as propostas dos usuários diretamente relacionadas aos direitos sociais. E a explicação

\footnotetext{
${ }^{5}$ É muito significativo que se registre o fato do Código de Ética Médica - Resolução CFM $n^{\circ} 1246 / 88$, portanto, inspirado pelo mesmo movimento que provocou o surgimento do SUS, explicite um efetivo comprometimento com a saúde do ser humano. A propósito vale transcrever o seu Artigo 9: “A medicina não pode, em qualquer circunstância ou de qualquer forma, ser exercida como comércio.
} 
parece ser simples: as desigualdades tendem a perpetuar-se com a ausência do Estado, o que é notório, particularmente na periferia. A comparação das propostas nos leva a perceber as desigualdades e injustiças na ausência do exercício de direitos sociais. E o espaço das conferências não é, aí, apenas de denúncia dessa realidade mas de reparação propositiva.

O espaço público, no entanto, não abole o conflito, pois este é inerente à pluralidade do social; todavia, uma vez aberto à diversidade dos interesses, os critérios pelos quais a uns e não a outros são atribuídos direitos tendem a ser questionados como injustos e se tornam insustentáveis. (LEFORT, 1987, p.62-63).

Nesse sentido, as proposições sobre controle social permitem reafirmar a análise desenvolvida, vejamos.

Das 42 propostas agrupadas no tema "Controle Social", os prestadores de serviço apresentaram apenas quatro, quais sejam: manutenção da composição do atual Conselho Municipal (com 16-membros e paridade igual à da Conferência); - redefinição da responsabilidade sobre a política de saúde nos três níveis de governo: municipal, estadual e federal; - definição de uma política mais adequada entre setor privado e SUS; - reestudar as condições de saúde da cidade (com participação da sociedade civil, para definir um programa de atuação e prioridades).

Para este mesmo tema, os usuários apresentaram 15 proposições, como seguem: - reativar o jornal COMUSA (Conselho Municipal de saúde) para divulgação de todas as atividades relativas à saúde, inclusive prestação de contas dos gastos com a saúde; institucionalizar os Conselhos Regionais para incorporar à estrutura de saúde do Município; - reativar os Conselhos de Habitação e Segurança e criar o de Medicina do Trabalho; - controle eficiente do SUS e, especialmente, dos serviços médicos para doentes mentais; articular atividades de saúde entre UBS e entidades populares; estruturar a Comissão Intersetorial de Saúde dos Trabalhadores vinculada ao Conselho Municipal de Saúde; - estabelecer periodicidade para conferências municipais de saúde do trabalhador; - ampliar a representação do Conselho Municipal de Saúde para 32 membros, (assegurando a paridade atual); - garantir que o controle de emergência dos hospitais seja feito pelo Conselho Municipal de Saúde. 
Neste tema, as propostas de um e outro segmento são claramente opostas: enquanto os prestadores de serviço defendem a manutenção das condições atuais de controle, não havendo nenhuma novidade em suas posições, os usuários, claramente, buscam deslocar, de modo mais enfático, o controle da saúde pública para a população, através da ampliação do Conselho Municipal de Saúde, da criação e do revigoramento de novos conselhos, assim como da publicização de todas as práticas no setor da saúde pública.

Nota-se que a questão do controle social é crucial para assegurar a implantação do SUS, pois este representa uma mudança de filosofia que envolve não apenas o acesso ampliado à população da oferta pública de serviços médicos, mas a própria autoridade médica e toda a instituição que a sustenta é abalada quando a democratização política do controle da prática médica substitui a autoridade de um saber sobre a saúde até então não questionado (LUZ, 1997). E isto é relevante porque numa sociedade como a nossa em que a hierarquia se cristaliza em privilégios, a perspectiva igualitária se põe necessariamente como negadora da ordem instituída. Mudança, portanto, que não se faz sem a exacerbação do conflito.

Assim, não se trata, apenas, da fiscalização das ações que estão sendo desenvolvidas, nem só de garantir que os recursos financeiros que alimentam o sistema tenha o seu fluxo desimpedido. $\mathrm{O}$ controle social envolve a sociedade autônoma, envolve sujeitos sociais na construção dos seus próprios direitos. É este o sentido das conferências dentro da filosofia do SUS - a possibilidade da construção de uma sociedade não apenas livre da opressão, mas na qual a própria liberdade possa ser um elemento constitutivo de sua instituição.

\section{Considerações finais}

Temos como certo, e não há nenhum mérito nisso, que a análise feita ficou muito longe de esgotar as possibilidades oferecidas pelo material pesquisado. E se há relevância no estudo apresentado, esta se deve ao fato de se buscar resgatar uma experiência possível de ser mantida, como alternativa que se contrapõe à realidade marcadamente 
mercadológica, assim parece, com toda a perplexidade que nos causa com relação à exclusão socioeconômica, é que parece manter-se inflexível como modelo neoliberal, enchendo-nos de dúvidas no presente e incertezas no futuro.

As conferências são exemplificadoras dessa possibilidade de resistência à negação de direitos, ao permitir que um processo negociado, público, de participação na riqueza social, torne-se realidade para um contingente populacional mais amplo. Mas, mais do que assegurar acesso aos bens sociais, as conferências possibilitam a construção política desse acesso, a partir de uma noção de direito do que seja justo e injusto.

Parece ter ficado claro que as conferências são muito mais que meros institutos através dos quais as populações asseguram direitos sociais - assim entendida a satisfação das necessidades de saúde. É o fato político, mais que o social, o que é significativo nas conferências; é o sentido político que o espaço das conferências assume ao abrigar a pluralidade de atores com interesses dificilmente convergentes, tornando esse espaço não necessariamente de consenso, mas de discussão, de dissenso, de persuasão, e, sobretudo de aprendizado, a partir de uma pedagogia de direitos que implica o reconhecimento da alteridade. Daí ser um espaço imprescindível de interlocução política, sem o qual não há exercício da cidadania; espaço a partir do qual os acordos e decisões são feitos e desfeitos pela ação autônoma dos sujeitos sociais e políticos.

Para terminar esse registro e considerações, parece-me não haver dúvidas que as conferências se caracterizam como um espaço público que não apenas permite a oportunidade do ver e ser visto, ouvir e ser ouvido para assegurar a satisfação de necessidades, mas, sobretudo, para, coletivamente e, a apartir do embate de idéias, construir o sentido das coisas comuns (TELLES, 1994; SILVEIRA, 1997). Mais afinado com a teorização de Hannah Arendt (1990), o conceito de espaço público ganha uma dimensão de liberdade, pois só pode ser efetivado na companhia dos outros, e assim, as conferências devolvem a política à sociedade. 


\section{Referências Bibliográficas}

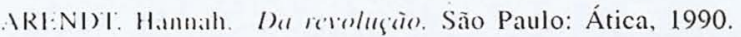

BOJA. Jordi. A participação citadina. Espaço \& Debates, São Paulo, v.8, n.24, p.14, 1988.

CHAUÍ, Marilena. O discurso competente. In: Cultura e Democracia, o discurso competente e outras falas. 5.ed. São Paulo: Brasiliense, 1990.

Conformismo e resistência: aspectos da cultura popular no Brasil. São Paulo: Brasiliense, 1993.

DIMITROV, Pedro. Saúde pública no Sistema Único de Saúde: SUS. [Brasília]: CUT/FUNDACENTRO, 1996.

DRAIBE, Sônia J. (Coord.); VIANA, A L. D’Ávila; SILVA, P.L. Baro. Desenvolvimento de Políticas de saúde nos anos 80: o caso brasileiro. Campinas, NEPP/ UNICAMP, 1990.

ESPING-ANDERSEN, Gosta. A três economias políticas do Welfare State. Lua Nova, n.24, p.85-116, set., 1991.

JACOBI, Pedro. Administração Municipal, Descentralização e Participação: uma agenda de questões e indagações no contexto da transição. São Paulo: CEDEC/USP, 1989. mimeo.

LEFORT, Claude. A invenção democrática, os limites do totalitarismo. 2.ed. São Paulo: Brasiliense, 1987.

LUZ, Terezinha M. Novas realidades em Saúde, novos objetos em Ciências Sociais. In: CANESQUI, Ana Maria (Org.). Ciências Sociais e Saúde. São Paulo, HUCITEC, 1997. p.79-85.

MULLER NETO, Júlio. Políticas de saúde no Brasil: a descentralização e seus atores. Saúde em Debate, n.31, p.54-66, 1991.

NEVES, Gleisi H. Descentralização ou desconcentração dos serviços de saúde ? Rio de Janeiro: IBAM, 1987.

OLIVEIRA, Francisco de. O surgimento do antivalor. Novos Estudos Cebrap, São Paulo, n.22, p.8-28, out., 1988. 
OTTMANN, Götz. Movimentos sociais urbanos e democracia no Brasil. Novos Estudos Cebrap, n.41, p.186-207, mar., 1995.

PAOLI, Maria C; SADER, Éder. Sobre classes populares no pensamento sociológico brasileiro". In: CARDOSO, Ruth (Org.). A aventura antropológica. Rio de Janeiro: Paz e Terra, 1986.

PAOLI, Maria C. Trabalhadores cidadania, experiências do mundo público na história do Brasil moderno. Estudos Avançados, v.3, n.7, p.40-66, set./dez. 1989.

SILVEIRA, Ricardo de Jesus. As Associações de Moradores e a Construção do Espaço Público: um exercício de cidadania. 1997. Tese (Doutorado).

Departamento de Sociologia, Universidade de São Paulo, São Paulo, 1997.

TEIXEIRA, S.M. Fleury. Descentralização dos Serviços de Saúde: dimensões analíticas. Cadernos Nona, n.1, p.27-37, 1992.

TELLES, Vera da S. Pobreza, movimentos sociais e cultura política: notas sobre as difíceis relações entre pobreza, direito e democracia. In: DINIZ, E; LEITE LOPES, J; PRANDI, R. (Orgs.). O Brasil no rastro da crise. São Paulo: Hucitec, 1994.

Direitos Sociais, Afinal do que se trata? Belo Horizonte: Ed. UFMG, 1999.

\section{Abstracts}

The text is a reflection on the conferences of health of Londrina. It tries to demonstrate that the conferences are characterized as political space, par excellence, because they are going besides the mere construction of social rights in the extent of the health. They correspond to spaces that shelter a plurality of social actors and conflicts of interests, allowing the action of being politicized of the social subjects and, in this sense, the full exercise of the citizenship.

Key-words: political space; democracy; citizenship. 